\title{
Effect of Repeated Sephadex Injection with or without Escherichia coli Lipopolysaccharide on Growth, Immunocompetent Organ Weight and Plasma Alpha 1 Acid Glycoprotein Concentration in Broiler Chicks Reared in Different Stocking Density
}

\author{
Kazuaki TAKAHASHI, Yukio AKIBA and Keiji TAMURA ${ }^{\prime}$ \\ Faculty of Agriculture, Tohoku University, Aoba-ku, Sendai-shi 981-8555, Japan \\ ${ }^{\text {I }}$ Saikin Kagaku Institute, Aoba-ku, Sendai-shi 981-0917, Japan \\ (Received August 19, 1999 ; Accepted February 18, 2000)
}

\begin{abstract}
Effect of immune stimulation and stocking density on growth, immunocompetent organ weight and plasma alpha 1 acid glycoprotein (AGP) concentration was studied in male broiler chicks to develop a laboratory model for studying a chronic immunological stress. Sephadex (G-50, $250 \mathrm{mg}$ / $\mathrm{kg} \mathrm{BW}$ ) and/or Escherichia coli lipopolysaccharide (LPS, serotype $0127: \mathrm{B} 8500 \mu \mathrm{g} / \mathrm{kg} \mathrm{BW}$ ) were used as agents to stimulate the immune system. Chicks were reared in two different stocking densities (217 and $650 \mathrm{~cm}^{2}$ per chick) in experiment 1 , and kept at $650 \mathrm{~cm}^{2}$ per chick in experiment 2 . In experiment 1 , injection of Sephadex alone every other day over 10 days tended to reduce body weigh gain as compared to a saline injected control, but the effect was not significant. Injections with Sephadex and LPS on alternate days over 10 days significantly reduced body weight gain in chicks kept at $650 \mathrm{~cm}^{2}$ per chick. In experiment 2, injections of LPS and Sephadex on alternative day over 5 days significantly reduced body weight gain and feed consumption. Relative spleen weights were higher in the chicks treated with LPS and Sephadex than those in the control chicks in both experiments. Alternate injections of LPS and Sephadex, or Sephadex injection alone increased AGP concentration in plasma in both experiments. The results suggested that injection with Sephadex and LPS on alternate days over 5 days mimics responses to a chronic stress such as reduction in growth and feed utilization, enlargement of liver and spleen, and activation of certain inflammatory responses. This laboratory model could be a useful way for finding novel nutrient(s) to alleviate the decreased rates of body weight gain and feed consumption by immunological stress.
\end{abstract}

Animal Science Journal 71 (3) : 268-273, 2000

Key words : Immunological stress, Growth, Organ weight, $\alpha$ 1-acid glycoprotein, Broilers

Exposure of animals to infectious or inflammatory agents not only induces immune responses in the host, but also causes metabolic changes that lead to decreased rates of body weight gain and feed consumption $^{3-8,10,15,17,19,203}$. One of the goals for modulating the immune system by nutrition is to alleviate decreased performance following immune stimulation without affecting the immune or inflammatory response per se. Development of a laboratory model with decreased rates of body weight gain and feed consumption by immunological stress is important to find novel nutrient(s) for alleviating those metabolic changes.

Administrations of Escherichia coli LPS, sheep

Corresponding : Kazuaki TAKAHASHI (fax : \$81(0) 22-717-8691, e-mail : taka@bios.tohoku.ac.jp) 
erythrocytes and Sephadex into chicks have been known to stimulate macrophage/monocyte ${ }^{5,7)}$. Klasing et al..$^{5)}$ reported reduction of growth and feed utilization by frequent injections of immunogens such as LPS, sheep erythrocytes and Sephadex in chicks in a model system for studying immunological stress. However, our previous experiments ${ }^{13,17)}$ showed that repeated injections of E. coli LPS (serotype, 0111 : B4) did not affect growth rate and feed utilization in chicks.

Stocking density is a factor of non-inflammatory stress and affects growth and plasma corticosterone concentration $^{2,99}$, which is also a physiological indicator of chicks subjected to stressful conditions, although our previous study showed that body weight gain and feed utilization for 14 days in chicks reared in a high stocking density did not differ from that in chicks kept at a low stocking density ${ }^{13)}$.

It has been considered that exposure of animal to several stressors with low intensity may cause growth reduction and metabolism defects. In the present experiment, we determined the possibility to develop a stable laboratory model with decreased rates of body weight gain and feed consumption by relatively low dose of LPS and Sephadex injections, and by change in stocking density.

\section{Materials and Methods}

\section{Animals, diets and stocking density}

Male broiler chicks (Ross strain) were housed in a battery brooder with electronic heater and fed a commercial broiler starter diet until 17 days of age. In both experiments, chicks were selected from one and a half larger population to obtain uniform body weight. In experiment 1 , chicks were randomly assigned to six pens of 6 chicks each, and fifteen pens of 2 chicks each in a cage (about $30 \mathrm{~cm}$ wide $\times 45 \mathrm{~cm}$ length) to achieve stocking density of $217 \mathrm{~cm}^{2}$ and $650 \mathrm{~cm}^{2}$ per chick per cage, respectively. They were fed a commercial starter diet (CP 22\%, ME 3,000 kcal/g) ad libitum for 11 days. Length of feeder for groups with 6 chicks per cage was twice as that for 2 chicks per cage and diet was given 2 or 3 times a day to allow accessing feed freely. In experiment 2 , chicks were randomly assigned to twenty pens of 2 chicks to achieve stocking density of $650 \mathrm{~cm}^{2}$ per chick. They were given a diet (CP 23\%, ME $3,100 \mathrm{kcal} / \mathrm{kg}$ ) ad libitum for 12 days, which consisted of $47.87 \%$ corn, $30 \%$ soybean meal, $3.99 \%$ isolated soybean protein, $3.64 \%$ soybean oil, $10 \%$ glucose, $1.21 \%$ calcium carbonate, $1.78 \%$ calcium phosphate, $0.42 \%$ sodium chloride, $0.29 \%$ DL-methionine, $0.4 \%$ vitamin mixture and $0.4 \%$ mineral mixture.

\section{Immunological stimulation}

E. coli LPS (serotype 0127 : B8, Sigma, St Louis, MI, USA) was dissolved in sterilized saline at a concentration of $500 \mu \mathrm{g} / \mathrm{ml}$. A $5 \mathrm{~g}$ Sephadex G-50 superfine (Pharmacia, Piscataway, NJ, USA) was dissolved in $100 \mathrm{~m} l$ sterilized saline ( $9 \%$ sodium chloride solution). In experiment 1 , half of the chicks kept at 217 $\mathrm{cm}^{2}$ of stocking density during the final 11 days of the experiment were intraperitoneally injected with SephadexG-50 at $250 \mathrm{mg} / \mathrm{kg}$ BW every other day and were also given the saline the other days. One third of the chicks kept at $650 \mathrm{~cm}^{2}$ were injected with SephadexG-50 on days 1, 3, 5, 7 and 9, and they were also given the saline the other days. Another one third of the chicks kept at $650 \mathrm{~cm}^{2}$ were intraperitoneally injected with SephadexG-50 at 250 $\mathrm{mg} / \mathrm{kg} \mathrm{BW}$ on days 1, 3, 5, 7 and 9, and with LPS at $500 \mu \mathrm{g} / \mathrm{kg} \mathrm{BW}$ on days $2,4,6,8$ and 10 . The remaining groups at both stocking densities were injected with the saline everyday and served as the control chicks. In experiment 2, chicks were intraperitoneally injected with LPS on days 1,3 and 5 and SephadexG-50 on days 2 and 4 during final 6 days of the experiment. The remaining chicks (control group) were injected with saline alone.

Blood sampling, determinations of plasma $\alpha 1$-acid glycoprotein (AGP) concentration and organs weight

A blood sample was taken on days 6 and 11 before the immune stimulation of that day in experiment 1 . In experiment 2, a blood sample was taken on days 2 and 6 before the immune stimulation. Liver, spleen, bursa and thymus from 6 chicks selected randomly in each group were removed at the end of experiments and weighed. The determinations of AGP concentrations in plasma were performed as reported previously $^{14)}$. 
TAKAHASHI, AKIBA and TAMURA

Table 1. Effects of Sephadex injection with or without Escherichia coli lipopolysaccharide (LPS), and stocking density on growth and feed intake in broiler chicks (experiment 1)

\begin{tabular}{|c|c|c|c|c|c|}
\hline \multirow{2}{*}{$\begin{array}{l}\text { Stocking density } \\
\left(\mathrm{cm}^{2} / \text { bird }\right)\end{array}$} & \multirow{2}{*}{ Treatment } & \multicolumn{2}{|c|}{ Body weight gain ${ }^{1\}}$} & \multicolumn{2}{|c|}{ Feed intake ${ }^{2)}$} \\
\hline & & (g/5days) & (g/11days) & (g/5days) & (g/11days) \\
\hline \multirow[t]{2}{*}{217} & Saline & $338 \pm 12$ & $645+15$ & $488 \pm 6$ & $1,042 \pm 15$ \\
\hline & Sephadex & $329 \pm 17$ & $613 \pm 28$ & $468 \pm 11$ & $989 \pm 16$ \\
\hline \multirow[t]{3}{*}{650} & Saline & $345 \pm 16^{a}$ & $700 \pm 17^{a}$ & $490 \pm 7$ & $1,081 \pm 12$ \\
\hline & Sephadex & $345 \pm 12^{\mathrm{a}}$ & $672 \pm 29^{a b}$ & $508 \pm 15$ & $1,099 \pm 25$ \\
\hline & Sephadex + LPS & $303 \pm 11^{b}$ & $613 \pm 26^{\circ}$ & $471 \pm 11$ & $1,021 \pm 37$ \\
\hline
\end{tabular}

1) Mean $\pm S E$ of 18 and 12 observations in groups at 217 and $650 \mathrm{~cm}^{2} /$ chicks, respectively.

${ }^{2)}$ Mean $\pm \mathrm{SE}$ of 3 and 6 observations in groups at 217 and $650 \mathrm{~cm}^{2} /$ chicks, respectively.

Different superscript letters in a column in the same stocking density group show significant difference $(\mathbf{P}<0.05)$.

Table 2. Effects of Sephadex injection with or without Escherichia coli lipopolysaccharide (LPS), and stocking density on organ weights in broiler chicks (experiment 1$)^{1)}$

\begin{tabular}{|c|c|c|c|c|c|}
\hline \multirow{2}{*}{$\begin{array}{l}\text { Stocking density } \\
\quad\left(\mathrm{cm}^{2} / \text { bird }\right)\end{array}$} & \multirow{2}{*}{ Treatment } & Liver & Spleen & Bursa & Thymus \\
\hline & & \multicolumn{4}{|c|}{$(\mathrm{g} / \mathrm{kg} \mathrm{BW})$} \\
\hline \multirow[t]{2}{*}{217} & Saline & $23.64 \pm 0.91$ & $1.18 \pm 0.16$ & $2.07 \pm 0.25$ & $3.52 \pm 0.32$ \\
\hline & Sephadex & $26.24 \pm 2.24$ & $1.24 \pm 0.28$ & $1.57 \pm 0.11$ & $3.60 \pm 0.34$ \\
\hline \multirow[t]{3}{*}{650} & Saline & $22.91 \pm 0.80^{\mathrm{b}}$ & $1.09 \pm 0.08^{b}$ & $3.22 \pm 0.30$ & $5.80 \pm 1.00$ \\
\hline & Sephadex & $25.31 \pm 0.60^{\mathrm{a}}$ & $1.04 \pm 0.07^{\mathrm{b}}$ & $2.66 \pm 0.33$ & $3.89 \pm 0.41$ \\
\hline & Scphadex + LPS & $24.53 \pm 0.84^{\mathrm{ab}}$ & $1.56 \pm 0.08^{\mathrm{a}}$ & $2.43 \pm 0.26$ & $3.91 \pm 0.31$ \\
\hline
\end{tabular}

1) Mean $\pm \mathrm{SE}$ of 6 observations.

Different superscript letters in a column in the same stocking density group show significant difference $(\mathbf{P}<0.05)$.

\section{Statistical analysis}

Statistical test was applied to analyze the data using SAS (SAS Institute, Cary, NC, and USA). Mean value within the same stocking density was compared using Duncan's multiple range test or t-test when main effect was statistically significant $(\mathbf{P}<0.05)$.

\section{Results}

Tables 1 and 2 show effects of immune stimulation and stocking density on growth, feed intake and organs weight of broiler chicks in experiment 1 . Sephadex injection every other day over 5 and 10 days tended to decrease body weight gain and feed intake in chicks kept at 217 and $650 \mathrm{~cm}^{2}$ per chick, but the reductions were not significant. Among the chicks kcpt at $650 \mathrm{~cm}^{2}$ per chick, injection of Sephadex and
LPS on alternate days over 5 and 10 days significantly reduced body weight gain and increased spleen weights at the end of the experiment as compared to the control.

Table 3 shows effects of immune stimulation and stocking density on plasma AGP concentration of broiler chicks in experiment 1. Plasma AGP concentration was significantly increased by Sephadex injection in chicks kept at $217 \mathrm{~cm}^{2}$ per chick on days 6 and 11 as compared to the control $(\mathbf{P}<0.05)$. Plasma AGP concentration in the chicks injected with LPS and Sephadex was higher than that in the control on days 5 and 11 , and in the chicks injected with Sephadex alone on day $11(\mathrm{P}<0.05)$.

Table 4 summarizes the results of experiment 2 . Injections with LPS and Sephadex on alternate days 
Immunological Stress and Responses of Chicks

Table 3. Sephadex injection with or without Escherichia coli lipopolysaccharide (LPS), and stocking density on plasma alpha 1 acid glycoprotein (AGP) concentration in broiler chicks (experiment 1$)^{1)}$

\begin{tabular}{clcc}
\hline \hline \multirow{2}{*}{$\begin{array}{c}\text { Stocking density } \\
\left(\mathrm{cm}^{2} / \text { bird }\right)\end{array}$} & \multicolumn{1}{c}{ Treatment } & \multicolumn{2}{c}{ AGP concentration (mg/l) } \\
\cline { 3 - 4 } 217 & Saline & Day 6 & Day 11 \\
\hline \multirow{2}{*}{650} & Sephadex & $542 \pm 86^{\mathrm{a}}$ & $681 \pm 86^{\mathrm{a}}$ \\
& Saline & $299 \pm 44^{\mathrm{b}}$ & $255 \pm 26^{\mathrm{b}}$ \\
& Sephadex & $392 \pm 32^{\mathrm{b}}$ & $481 \pm 61^{\mathrm{a}}$ \\
& Sephadex + LPS & $598 \pm 62^{\mathrm{a}}$ & $607 \pm 91^{\mathrm{a}}$ \\
\hline
\end{tabular}

1) Mean $\pm \mathrm{SE}$ of 6 observations. Different superscript letters in a column in the same stocking density group show significant difference among the treatments $(\mathbf{P}<0.05)$.

Table 4. Effects of injection on alternate days with Escherichia coli lipopolysaccharide (LPS) and Sephadex on growth, organs weight and plasma alpha 1 acid glycoprotein (AGP) concentration in broiler chicks (experiment 2)

\begin{tabular}{lccc}
\hline \hline & & \multicolumn{2}{c}{ Treatment } \\
\cline { 3 - 4 } & & Saline & LPS + Sephadex \\
\hline Body weight gain $^{1)}$ & $(\mathrm{g} / 5$ days $)$ & $350 \pm 17$ & $238 \pm 34 *$ \\
Feed intake $^{2}$ & $(\mathrm{~g} / 5$ days $)$ & $534 \pm 22$ & $399 \pm 50^{*}$ \\
Liver weight $^{3 /}$ & $(\mathrm{g} / \mathrm{kg} \mathrm{BW})$ & $24.2 \pm 0.6$ & $34.6 \pm 3.0^{*}$ \\
Spleen weight $^{3\rangle}$ & $(\mathrm{g} / \mathrm{kg} \mathrm{BW})$ & $1.29 \pm 0.09$ & $2.06 \pm 0.17^{*}$ \\
Bursa wcight $^{3)}$ & $(\mathrm{g} / \mathrm{kg} \mathrm{BW})$ & $3.21 \pm 0.21$ & $3.09 \pm 0.28$ \\
Thymus weight $^{3)}$ & $(\mathrm{g} / \mathrm{kg} \mathrm{BW})$ & $5.01 \pm 0.30$ & $4.55 \pm 0.52$ \\
Plasma AGP $^{()}$ & $(\mathrm{mg} / \mathrm{l})$ & & \\
$\quad$ & & $217 \pm 37$ & $893 \pm 101^{*}$ \\
Day 2 & & $224 \pm 30$ & $1,036 \pm 199^{*}$ \\
\hline
\end{tabular}

1"Mean $\pm S E$ of 10 observations. ${ }^{2)}$ Mean $\pm S E$ of 5 observations.

3) Mean $\pm \mathrm{SE}$ of 6 observations.

* significant difference between the treatments $(\mathrm{P}<0.05)$.

over 5 days reduced body weight gain and feed intake, but increased plasma AGP concentration and relative liver and spleen weights.

\section{Discussion}

LPS and/or Sephadex injection increased plasma AGP concentration throughout the experimental periods, regardless of the stocking density in both experiments. Since AGP has been known to be a positive acute phase protein in chicks, and an increase in plasma AGP concentration was an indicator for an increase in IL-1 activity and mitogenic response of splenocyte by an inflammatory agent ${ }^{15,17)}$, LPS and/or Sephadex injections enhanced the inflammatory response despite differences in kind and intensity of stressor(s) loaded in the present study. Animals reared in a dirty environmental condition activate chronic immune system and resulted in alternation of 


\section{TAKAHASHI, AKIBA and TAMURA}

normal metabolic responses ${ }^{7,10)}$. Metabolic responses to chronic immune system activation accompany with reduced rate of growth and feed utilization, and enlargement of liver and spleen in chicks and pigs $^{5,10,16,20)}$. In the present study with chicks, immune stimulation induced by the injections of LPS and Sephadex on alternative days significantly reduced growth and feed intake with enlargement of liver and spleen. The longer-term injection of Sephadex alone in chicks reared in $217 \mathrm{~cm}^{2}$ per chick also has a similar response to injections with LPS and Sephadex. These results suggest that repeated injections of LPS and Sephadex every day, or Sephadex injection every other day for a long period together with rearing a high stocking density resulted in decreased rates of body wcight gain and feed consumption and enhanced inflammatory or immune responses. Hence, our procedures using LPS and Sephadex, and changing stocking density might suggest a possibility to reproduce the reduced rate of growth and feed utilization observed in dirty environmental condition. Although earlier experiments showed that immunogen-injected chicks consumed less feed and gained weight at a slow rate than a saline-injected chicks ${ }^{5,6,8,19}$, an advantage of using our system is that it is able to control the extent and intensity of stress expression as compared to the other model system previously reported ${ }^{5,6,8,19)}$.

Klasing et $a l .^{53}$ reported reduction of growth and feed utilization by frequent injections of immunogens such as LPS, sheep erythrocytes and Sephadex in chicks in a model system for studying immunological stress. However, our previous experiments ${ }^{13,17}$ showed that repeated injections of $E$. coli LPS (serotype, $0111:$ B4) did not affect growth rate and feed utilization in chicks. In the present experiment, injection with LPS (serotype, 0127: B8) reduced body weight gain and feed intake even when chicks received Sephadex. Webel et al. ${ }^{19)}$ showed that the same serotype of LPS as with the present experiment induced chronic anorexia as well as sickness behavior over assay periods of 9 to 11 days. These results suggested that selection of agents of immune stimulation would be an important factor to induce chronic immunological stress with reduction of growth, and that $E$. coli LPS (serotype, 0127: B8) would have much potential to reduce growth performance than the serotype 0111 : B4.

In experiment 1 , we did not observe a significant reduction of feed intake regardless of the type of immunological stimulation. In contrast, injection with LPS and Sephadex on alternate days markedly reduced feed intake for 5 days in experiment 2 . Klasing and Barenes ${ }^{6)}$ indicated that chicks fed a diet containing corn gluten meal had less metabolic responses to immunological stress than those fed a cornsoybean meal based diet did. Korver and Klasing ${ }^{8)}$ showed that dietary fish oil modulated the response as compared to dietary corn oil or olive oil in chicks. Roura et al. ${ }^{10)}$ demonstrated that more than $3,200 \mathrm{kcal}$ per $\mathrm{kg}$ diet of energy content also reduced the metabolic responses of chicks to immunological stress. Our previous experiment ${ }^{15)}$ showed that dietary protein concentration modulated the metabolic responses to immunological stress. Thus, nutrient composition and ingredients in diet used would modulate the metabolic responses caused by immunological stress. Therefore, a possible explanation for the difference in responses of feed intake in experiments 1 and 2 would be due to the difference in nutrient composition and ingredients used in diets which should be considered an important factor to develop a model system for studying chronic immunological stress with reduction of growth.

\section{References}

1) Curtis MJ, Flack IH. Effect of Escherichia coli endotoxins on the concentration of corticosterone and growth hormone in the plasma of the domestic fowl Research in Veterinary Science, 28 : 123-127. 1980.

2) Dafwang II, Cook ME, Sunde ML. Interaction of dietary antibiotics supplementation and crowding density on broiler chick performance and immune response. British Poultry Science, 28 : 47-55. 1987.

3) Friedman H, Newton C, Widen R, Klein T, Spitzer JD. Continuous endotoxin infusion suppresses rat spleen cell production of cytokines. Proceedings of the Society Experimental Biology and Medicine, 199 : 360 -364. 1992.

4) Grimble RF. Dietary manipulation of the inflammatory response. Proceedings of the Nutrition Society, 51 : 285-294. 1992.

5) Klasing KC, Laurin DE, Peng RK, Fry DM 
Immunologically mediated growth depression in chicks : influence of feed intake, corticosterone and interleukin-1. Journal of Nutrition, $117: 1629-1637$. 1987.

6) Klasing KC, Barnes DM. Decreased amino acid requirements of growing chicks due to immunological stress. Journal of Nutrition, $118: 1158-1164$. 1988.

7) Klasing KC. Nutritional aspects of leukocytic cytokines. Journal of Nutrition, 118 : 1436-1446. 1988.

8) Korver DR, Klasing KC. Dietary fish oil alters specific and inflammatory immune responses in chicks. Journal of Nutrition, 127 : 2039-2046. 1997.

9) Pesti GM, Howarth B. Efects of population density on the growth, organ weights and plasma corticosterone of young broiler chicks. Poultry Science, $62: 1080-1083.1983$.

10) Roura E, Homedes J, Klasing KC. Prevention of immunological stress contributes to the growthpromoting ability of dietary antibiotics in chicks. Journal of Nutrition, 122 : 2382-2390. 1992.

11) Spitzer JA, Friedman H, Newton C, Widen R, Pross $\mathrm{S}$, Klein TS. Suppressed in vitro blastogenic responsiveness of rata spleen cells after continuous infusion of endotoxin by an implanted osmotic pump. Proceeding of the Society for Experimental Biology and Medicine, $186: 21-26.1987$.

12) Sunwoo HH, Nakano T, Dixon WT, Sim JS. Immune responses in chickens against lipopolysaccharide of Escherichia coli and Salmonella typhimurium. Poultry Science, 75 : 342-345. 1996.

13) Takahashi K, Nishimura H, Akiba $Y$, Moriguchi $M$. Effect of stocking density and supplemental ascorbic acid on growth, organ weight, mixed function oxidase in hepatic microsomes, lipid metabolism and plasma corticosterone in male broiler chicks. Animal Science and Technology, 62: 829-838, 1991.

14) Takahashi K, Kaji S, Akiba Y, Tamura K. Plasma alpha 1 acid glycoprotein concentration in broilers. influence of age, sex and Escherichia coli lipopolysaccharide. British Poultry Science, 35 : 427-432. 1994.

15) Takahashi K, Yodogawa $S$, Akiba $Y$, Tamura K. Effect of dietary protein concentration on responses to Escherichia coli endotoxin in broiler chickens. British Journal of Nutrition, 74 : 173-182. 1995.

16) Takahashi K, Akiba $Y$, Matsuda A. Effect of a probiotic on immune responses in broiler chicks under different sanitary conditions or immune activation. Animal Science and Technology, $68: 537-544$. 1997.

17) Takahashi K, Ohta T, Akiba $Y$. Influcnces of dietary methionine and cysteine on metabolic responses to immunological stress by Escherichia coli lipopolysaccharide injection, and mitogenic response in broiler chickens. British Journal of Nutrition, 78 : 815-821. 1997.

18) Takahashi K, Miyake N, Ohta T, Akiba Y, Tamura $\mathrm{K}$. Changes in plasma $\alpha 1$-acid glycoprotein concentration and selected immune response in broiler chickens injected with Escherichia coli lipopolysaccharide. British Poultry Science, 39 : 152-155. 1998.

19) Webel DM, Johnson RW, Baker DH. Lipopolysaccharide-induced reductions in food intake do not decrease the efficiency of lysine and threonine utilization for protein accretion in chicks. Journal of Nutrition, $128:$ 1760-1766. 1998.

20) Williams NH, Stahly TS, Zimmerman DR. Effect of chronic immune system activation on body nitrogen retention, partial efficiency of lysine utilization and lysine needs of pigs. Journal of Animal Science, 75 : 2472-2480. 1997. 